\title{
Ser professor não é fácil
}

\author{
Jorge Correia Jesuino \\ Instituto Superior de Ciências do Trabalho e Empresas \\ Instituto Universitário de Lisboa
}

\section{Resumo}

O papel de professor no ensino secundário é examinado em seus modelos de gestão e liderança, requerendo-se competências-técnicas, dependentes de contingências específicas. $\bigcirc$ exercício docente depende tanto das suas características disposicionais e dos constrangimentos situacionais, como também dos factores sistêmicos das políticas e culturas pedagógicas. As pedagogias da essência com visão humanista privilegiam as relações verticais, as pedagogias da existência, mais horizontais, acentuam a personalização pedagógica, o respeito pelo aluno e o desenvolvimento da cooperação e da iniciativa. No caso português, o sistema acusa turbulência sem ter encontrado um equilíbrio, o que contribui para a ambiguidade do papel do professor.

Palavras chave: Profissão docente. Gestão e Liderança. Ensino Secundário em Portugal.

\section{Not easy to be teacher}

\section{Abstract}

The role of teacher at the high-school level is examined in the conceptual models of management and leadership requiring competencies-technical in accordance to contingent requirements. Effective teaching depends on dispositional and situational features, but also on the systemic constraints on policies and pedagogical cultures. The pedagogies of the essence with humanistic visionare more vertical, whereas the pedagogies of existence are more horizontal emphasizingpedagogical personalization, respect towards the student and development of cooperation and initiative. In the Portuguese case, the system is still turbulent withoutfind a balance and it contribute to the ambiguityof the role ofteacher.

Keywords: Teacher profession. Management and leadership. High school in Portugal. 


\section{No es fácil ser profesor}

\section{Resumen}

El papel del profesoren la educación secundaria es examinado en los modelos conceptuales de gestióny liderazgo, requiriendo habilidades técnicas dependientes de contingencias. El ejercicio dela profesión de docente depende de características disposicionales y limitacion es situacionales, también de factores sistémicos de políticas y culturas pedagógicas. Las pedagogías esencialistas con visión humanista son más verticales, mientras las pedagogías existencialistas son más horizontales, subrayando personalización pedagógica, respeto por el alumno y desarrollo de la cooperación e iniciativa. En el caso portugués, el sistema aún tiene turbulencia sin encontrar un equilibrio, lo que contribuye ala ambigüedad del rol de profesor.

Palabras clave: Profesión docente. Gestión y liderazgo. Educación secundaria in Portugal.

Nunca permiti que a Escola interferisse na minha educação (Mark Twain, 1835-1910)

\section{Introdução}

Procura-se no presente artigo abordar o tema da disciplina na Escola, através dos modelos que a literatura propõe sobre o exercício da liderança organizacional. É uma perspectiva possível e que, tanto quanto o autor saiba, tem sido menos explorada. É também uma defesa, dado ser esse o tema que o autor mais tem estudado e dado também que a sua experiência, quer como docente quer como investigador, se acha limitada ao nível do ensino universitário, registando apenas raras incursões no domínio do ensino secundário.

Julga-se, porém, que tem sentido considerar o exercício da docência, qualquer que seja o nível a que se exerça,como um exercício de liderança e de gestão, ou seja, como um exercício de poder mais próximo da influência e da persuasão do que da aplicação de ameaças e de sanções. E que, sob esse aspecto, os modelos de liderança podem dar uma contribuição válida para sugerir formas de intervenção mais eficazes na prevenção da indisciplina e na gestão dos conflitos que não obstante possam emergir. 
Oexercício da liderança enquanto exercício de poder, quando pensado no contexto do ensino/aprendizagem, conduz inevitavelmente a Foucault. Sem entrar em pormenores, aliás, conhecidos, vale a pena recordar a distinção que este autor introduz entre poder soberano e poder disciplinar. Foucault (1975) refere-se a momentos e práticas históricas:o poder soberano,como o próprio nome sugere, diria respeito ao poder concentrado numa figura central - o soberano -, enquanto o poder disciplinar teria um carácter sistémico, capilar, invadindo todo o tecido societal, designadamente através das instituições totais, na expressão de Goffman (1961), tais como os exércitos, os hospitais e as escolas. De recordar igualmente que essa disseminação do poder sistémico é tornada possível através das técnicas de fragmentação quadricular do espaço e do tempo e de dispositivos de controle como o panóptico, através dos quais o próprio conceito de disciplina se introduz naspráticas quotidianas. Isto não significa, porém, que o poder soberano tenha sido extinto, mas apenas que ele refluiu para os limites muito mais restritos dos papéis atribuídos aos agentes que operam o sistema. Esta visão não anda muito longe do pessimismo de Max Weber ao descrever as burocracias da modernidade como gaiolas de ferro regidas por uma legalidade baseada na razão instrumental. Também não estamos longe do estrutural-funcionalismo de Talcott Parsons, com a ideia de que o poder não constitui necessariamente um jogo de soma nula, em que uns perdem e outros ganham, mas antes um jogo em que todos ganham, embora em proporções variáveis.

Mas voltemos aos professores, aos alunos e à sala de aula. Aí o professor é ainda um pequeno soberano, porventura em vias de extinção, se admitirmos que cada vez mais a aprendizagem terá lugar através de dispositivos de ensino tecnologicamente padronizados e, sobretudo, se considerarmos a atmosfera de crescente rebeldia e inimputabilidade em que o ensino actualmente se processa. Mas não estaremos ainda nesse ponto. Ainda que cada vez menos reconhecida e acarinhada, a profissão ainda sobrevive.

Enquanto soberano, enquanto líder, os seus poderes acham-se limitados a montante pelos poderes disciplinares que, desde há séculos a esta parte, vêm organizando o contexto em que tal actividade se exerce e isso tanto no que se refere às múltiplas dimensões ergonómicas da arquitectura, em sentido lato do espaço-tempo da docência, como às técnicas pedagógico-didácticas e à definição dos programas curriculares a transmitir. Sob esse aspecto, o papel do professor do ensino secundário não difere substancialmente dos papéis que as 
modernas burocracias distribuem aos funcionários responsáveis pelo funcionamento regular do sistema, bem como pela sua reprodução. Na literatura sobre liderança organizacional, Kerr e Jermier (1978) introduziram o conceito de substitutos de liderança, justamente para significar que, em muitas das situações organizacionais, a liderança não reside tanto nos líderes como nas próprias normas e regulamentos constitutivos do sistema. Em tais casos, e desde logo, quanto mais pormenorizada a regulamentação, mais os papéis dos líderes se limitam a padrões comportamentais rígidos e menor será a sua capacidade de renovação do papel, ou seja, de inovarem, ensaiando diferentes iniciativas de trabalho conjunto. Haverá, todavia, que reconhecer que, mesmo em organizações submetidas a padrões mecânicos de socialização, o factor humano continua a revelar-se incontornável, tanto para o bem, pela capacidade inovadora que introduz,como para o mal, pelo erro ou perversidade não menos constitutivos do sistema.

É neste quadroque se inscreve a actividade do docente no seu papel de líder, cuja importância adquire um outro relevo quando abdicamos da perspectiva macro-sistémica e nos reportamos ao contexto mais próximo da sala de aula.

\section{Poder, influência e liderança}

Dispõe-se actualmente de um corpo razoavelmente extenso e de certo modo consensualizado sobre os conceitos de poder e influência, sobretudo quando encarados na perspectiva funcionalista da eficácia relativa dos seus efeitos. No âmbito da Psicologia Social, deve-se a French e Raven (1959) uma descrição, senãomesmo uma teoria relativa às fontes e modalidades de poder que,embora formulada nos anos 50, continuahoje a revelar-se válida.

Segundo estes autores, haveria que distinguir entre poderes ou, se preferirmos, fontes de poder, pessoais e posicionais. Poderes posicionais são os conferidos pelo sistema, ou seja, os poderes disciplinares que se traduzem em recompensas ou em punições. Poderes pessoais são os que derivam das próprias características do sujeito,como é o caso da competência - saber e/ ou saber como -, ou ainda do grau de atractividade e simpatia que transmite e que outros autores designam por poder de referência - o sujeito constitui-se como uma referência. A articulação entre os poderes pessoais e os poderes 
posicionais tem lugar através do poder legítimo - de todos o que apresenta características mais dinâmicas.

O conceito de legitimidade, segundo Max Weber (2005), está ligado ao conceito de autoridade. Por outras palavras, autoridade significa poder legítimo, ou seja, um poder cujo exercício é livremente aceite, sem contestação significativa. Weber distingue em seguida 3 tipos de legitimidade: (1) a tradicional - sempre se fez assim; (2) a carismática - baseada no carisma, ou seja, no poder pessoal, na acepção de French e Raven antes referida; e (3) racional-legal - assente nas leis construídas pela razão e como tal geralmente aceites. Note-se que, nesta formulação, a legalidade é apenas um tipo de legitimidade, além de que nem sempre o que é legal é legítimo,e nem sempre o que é legítimo é legal. Em grande medida, a mudança social opera-se através da deslegitimação da legalidade. Pensemos, por exemplo, nos castigos corporais nas escolas primáriasou nas resistências que houve que ultrapassar para a introdução da escola mista no ensino secundário.

Poder legítimo, na tipologia de French e Raven,é um poder dinâmico,é - poder que se exerce e se actualiza através duma gestão entre poderes posicionais e poderes pessoais, aqueles mais próximos da influência e persuasão. De algum modo, o exercício duma liderança institucional traduz-se no exercício dum poder legítimo, que the confere a capacidade de punir ou recompensar,capacidade essa a que será tanto menos necessário recorrer quanto maior for a sua capacidade de influenciar e persuadir através do capital de carisma pessoal. De notar ainda que, em regimes de prolongada estabilidade, a legitimidade tradicional, traduzida numa aceitação passiva do status quo, constitui um factor de facilitação para os actores do sistema, na medida em que são menos pressionados a um permanente esforço de legitimação.

Não será difícil aplicar este conjunto de noções à situação escolar onde o professor, enquanto líder, dispõe dos poderes disciplinares, no sentido restrito de punições e recompensas, que apenas reforçam os poderes disciplinares, no sentido de Foucault, inscrito na arquitectura do sistema. Certamente mais decisivos serão os poderes pessoais, ou seja, a capacidade de alcançar os objectivos da missão sem ter de recorrer a tais meios, aliás, tanto mais eficazes quanto mais permaneçam na sombra.

As teorias da liderança partem desta ideia-base e procuram, na sua vertente funcionalista, formar os responsáveis no exercício dos poderes soft 
ou,como diria o Presidente Truman, levar as pessoas a fazerem o que não desejariam espontaneamente fazer e a sentirem-se inclusivamente satisfeitas por isso. Esta perspectiva terá alguns contornos ideológicos, na medida em que dá uma importância crucial ao agentismo e ao voluntarismo, mas que em ultima análise deriva também dacentralidade do individualismo, porventura um efeito perverso antecipado na visão sistémica de Foucault. Atribuir aos líderes capacidade transformacional leva, por outro lado, a deslocar a análise da sociologia para a psicologia social, senão mesmo para a psicologia,quando,nomeadamente, se colocam em primeiro plano as características de personalidade dos líderes. Em contrapartida, os analistas europeus atribuem, regra geral, mais peso explicativo aos factores contextuais e designadamente ao grau em que os sistemas de ensino contribuem para reproduzir ou para corrigir as desigualdades sociais. Nesta perspectiva, os problemas disciplinares tendem a ser considerados marginais e resultantes sobretudo das assimetrias de acesso e consequentes desvios societais.

Num contexto societal pós-moderno, em que uma das marcas distintivas seráo culto do individualismo, da diferença e da expressão libertária, parece justificar-se maior atenção às práticas de liderança, não apenas enquanto técni34 cas de manipulação dos grupos humanos, mas sobretudo pela importância que atribuem aos destinatários do exercício do poder.

Colocar o doente, o clienteou, neste caso, o aluno no centro do sistema implica uma mudança não apenas retórica, mas sobretudo práticas empiricamente fundamentadas. A manipulação tem limites que a psicologia científica ajuda a identificar.

$\bigcirc$ interesse pelos efeitos das práticas de liderança em contextos quase-escolares manifesta-se, talvez pela primeira vez, com os estudos bem conhecidos de Lewin e Lippit (1938), ainda nos anos 30, imediatamente antes do início da $2{ }^{a}$ Guerra Mundial. Kurt Lewin era um psicólogo alemão, judeu,com um passado de investigação no domínio da psicologia da criança. A sua orientação teórica era gestaltista, mais holista do que individualista. Com o advento do nazismo refugiou-se nos Estados Unidos, onde prosseguiu uma carreira notável. É um dos pais fundadores da psicologia social experimental,com particular relevo para a dinâmica de grupos. Num dos primeiros estudos que realizou, procurava mostrar que a democracia parlamentar, tão atacada peloautoritarismo, então triunfante nos meios europeus e mesmo norte-americano, não era menos produtiva que a autocracia, podendo ter vantagens na atmosfera 
emocional dos grupos, reduzindo as tensões, promovendo a harmonia interna e contribuindo desse modo para uma disciplina espontânea dos liderados. A experiência que levou a efeito é por demais conhecida, dispensando detalhes. Recorrendo ao método experimental, treinou jovens adultos para exercerem o papel de monitores de grupos de adolescentes, cuja tarefa consistia emconstruírem modelos de aeronaves. Os "monitores" foram treinados para utilizarem três estilos de liderança: o estilo autocrático, o estilo democrático e o estilo laisser faire.

Oestilo autocrático traduzia-se na implementação de regras rígidas, impedindo os adolescentes de conversarem uns com os outros e exercendo um controlo rigoroso sobre os seus desempenhos, os quais se limitavam a seguir as instruções para a execução da tarefa. $\bigcirc$ estilo democrático inspirava-as em grande medida nas recomendações de Carl Rogers - directivo quanto à forma mas não quanto ao conteúdo - ou seja, os jovens podiam alterar os esquemas, inventar novas formas, o que implicava uma maior liberdade de participação e trabalho em grupo, mas também uma certa "indisciplina" relativa, resultante da participação e do trabalho em grupo. Finalmente, na condição laisser faire, o monitor não era directivo quanto à forma nem quanto ao conteúdo, alheando-se tanto das tarefas como da manutenção da disciplina do grupo.

Os resultados vieram validar as hipóteses de Lewin, e Lippit (1938): com a liderança autocrática obtinha-se o nível de produtividade requerido mas os adolescentes revelavam elevados níveis de tensão emocional, detectados pelo ruído e indisciplina geral com a ausência do monitor (chamado a atender um telefonema), enquanto sob aliderança democrática a produtividade não era significativamente mais baixa, mas em compensação observaram-se alternativas criativas e não havia explosões de indisciplina com a ausência foriada do monitor. Mas, eessa era a outra hipótese que Kurt Lewin quis ilustrar, a democracia tem regras - directividade quanto à forma - e não se deve confundir com a anarquia observada na condição laisser faire, onde tanto em termos de produtividade como de disciplina os resultados se revelaram medíocres.

As experiências de Lewin e Lippit, a que posteriormente se associou igualmente White, estão certamente datadas. $\bigcirc$ método experimental dava os primeiros passos, as hipóteses revestiam-se de alguma ingenuidade ideológica e não se verificou a sua validação posterior em contextos mais constrangedores dos curricula escolares, onde a variedade de condições é mais vasta e 
complexa. Em todo o caso, a ideia de distinguir entre diferentes estilos de liderança e sobretudo a de distinguir as dimensões relacionadas com a atmosfera emocional do grupo continua a constituir ainda hoje a ideia central subjacenteaos estudos sobre liderança organizacional.

Nas décadas de 50 e 60 apostava-se ainda na hipótese do líder universal, eficaz em todas as situações, fosse professor, sargento ou chefe de secção, e esse seria aquele que reuniria ambas as competências, tanto no domínio da tarefa específica a realizar como no relacionamento com o grupo liderado. As competências relacionadas com a tarefa consistem, em ultima análise, nas competências de gestão, ou seja, planear, organizar,coordenar e controlar e, claro, no caso específico do docente, ser conhecedor das matérias que lecciona e da pedagogia que lhe está associada. Quanto às competências relacionais, elas dizem respeito à capacidade deouvir, de apoiar, de ajudar, de motivar, de se oferecer como modelo, o que poderá ser decisivo para a manutenção de uma atmosfera de grupo harmoniosa, ausência de stress e satisfação generalizada. Todavia, veio posteriormente a reconhecer-se que os estilos ideais não são universais mas contingentes, ou seja, dependem dos grupos e das tarefas específicas a levar a efeito. A liderança eficaz varia, dessa forma, 36 com o contexto situacional e a competência dos líderes passa a consistir na capacidade de diagnóstico e na flexibilidade com que adequa o estilo à situação. Note-se que tais modelos são comportamentais, fazendo economia das características de personalidade dos líderes. Exige-se deles, e também nesse sentido são treinados, capacidade de diagnóstico psicológico, de inteligência emocional e de assertividade comunicacional, que nem sempre será fácil reunir.

Segundo Adair (2006), um autor inglês, a liderança poderia ser representada em termos dos diagramas de Venn como o lugar de intersecção da tarefa, dos indivíduos e do grupo como um todo. Algo que todo o professor possivelmente sabe, ainda que apenas por instinto. Por um lado, a matéria a leccionar, que desde logo exige competências técnicas e competências comunicacionais; por outro lado, cada caso é um caso, o que implica diferenciação ao nível diádico,como também ao nível do que Cattell (1961) designaria como a sintalidade do grupo - uma supra-entidade complexa resultante da própria dinâmica desenvolvida pelo grupo,com as suas fases e o seu ciclo de vida. Claro que nada disto é fácil e sobretudo, permita-se a insistência, quando a tradição já não é o que era. 
Sabemos hoje, ou julgamos saber,que, embora estas três dimensões sejam interdependentes e sempre interrelacionadas, haverá que começar por dar prioridade às tarefas, o que implica explicitar objectivos, regras do jogo, normas, critérios de avaliação, o que desde logo permite activar as dinâmicas individuais e intra-grupais, ainda que em estado latente.

A relação líder-grupo é a que naturalmente se segue e acompanha de resto a dinâmica, que se tornará tanto mais sustentada quanto mais se desenvolverem as relações diádicas, levando à construção de uma rede relacional idealmente auto-regulada. Os desenvolvimentos mais recentes na psicosociologia da liderança atribuem particular relevo a esta terceira faceta, que consiste em superar a fase de uma relação, ainda que correcta,com o grupo como um todo, para uma rede de múltiplas relações diádicas. A observação e análise sistemática mostram que, em muitos casos, tal passagem se limita a relações inter-diádicas preferenciais, levando à formação de um endogrupo,o grupo próximo,e de um exo grupo - o grupo dos restantes, indiferenciados ou mesmo ignorados. Esta constitui, aliás, uma das reclamações mais frequentes dos alunos, sobretudo em turmas numerosas, onde os docentes nem sempre conseguem construir uma rede equilibrada regida por normas equitativas e muito menos pelas normas da necessidade - ajudar os que mais precisam de ser ajudados.

As teorias contingenciais apoiadas em diagnósticos correctos levam, por outro lado, a recomendar uma maior austeridade e centração na tarefa, quando os grupos são mais difíceis - leia-se heterogéneos, irrequietos, incumpridores, desatentos -, o que possivelmente muitos docentes sabem e praticam, mesmo que intuitivamente ou por muitos anos de experiência. A vantagem de começar com a tarefa - curioso o slogan inglês que recomenda "não sorrir antes do Natal" - reside precisamente em começar por estabelecer uma distância, uma objectividade que a própria tarefa exige. E, sabemos todos, quer estejamos de um ou do outro lado da barricada, que os primeiros momentos, as primeiras aulas, as primeiras impressões são decisivas, ainda que em certos casos elas possam mudar com o tempo e com o próprio ciclo de vida do grupo. Diagnosticar o perfil dum grupo não é fácil, sobretudo quando ele se inicia com o próprio início do curso, ou seja, quando não tem história, enquanto grupo. Neste caso, o diagnóstico coincide com a própria dinâmica interactiva que o líder the imprime e com os retornos sucessivos que dele recebe. $\bigcirc$ grupo constrói-se a si próprio e o líder beneficiará em ser suficientemente humilde para reconhecer que nem tudo depende dele mas também que muito depende da 
sua actuação. Ser líder é também ser bode expiatório, como podemos observar a partir de exemplos quotidianos da cena política. Todavia a distância para a sala de aula não é grande e os efeitos perversos emergem um pouco por todo o lado.

Um fenómeno psicológico que aqui vem a propósito referir diz respeito ao "efeito de Pigmaleão", ou seja, a "profecia que se auto-realiza" Iself-fulfilling prophecy), que deu lugar a centenas de experiências em contexto escolar.

$\bigcirc$ efeito foi inicialmente identificado pelo sociólogo Robert Merton, mas deve-se a Robert Rosenthal (1968) a sua aplicaçãoà sala de aula. Publicou, aliás, um livro com esse título - Pigmaleão na sala de aula. Rosenthal começou por observar que colegas seus, cientistas que faziam experiências com ratos a percorrerem labirintos, quando convencidos que alguns dos ratos eram mais inteligentes, esses ratos aprendiam mais depressa e cometiam menos erros. $O$ resultado tinha algo de intrigante e levou Rosenthal a formular a hipótese de que, quando estamos convencidos de que um determinado sujeito com quem interagimos é ou não capaz de alcançar determinado resultado, desenvolvemos inconscientementeuma interacção que se revela instrumental para que a "profecia se realize". A aplicação no contexto escolar e mesmo noutros contex-

38 tos de formação profissional conduziu a validar tais hipóteses, constituindo hoje uma das técnicas mais recomendadas nas formações em liderança. Um resultado menos positivo de tais estudos, e que levou de resto à sua condenação em termos éticos, foi ter-se concluído que os bons desempenhos de alunos não incluídosnas expectativas dos docentes eram por estes atribuídos ao acaso e não às suas qualidades de aprendizagem - o mesmo fenómeno que já referimos anteriormente das díades preferenciais tendo como fundo uma rede indiferenciada e anónima de sujeitos condenados à passividade.

Uma vez mais o efeito terá mais tendência para se tornar perverso se utilizado desta forma restritiva, em vez da sua aplicação à própria dinâmica do grupo enquanto equipa onde não há personagens secundárias. Acresce que, mesmo ao nível diádico, o efeito só actua se o diagnóstico inicial for minimamente realista e sobretudo quando o próprio sujeito-alvo interiorizou a profecia e considera estar à altura do desafio de que é alvo. Tais práticas são correntes na psicologia desportiva e alertam para o papel importante que a formação neste domínio pode desempenhar na consolidação da autoconfiança dos alunos. 
Curiosamente, se dispomos de evidência empírica abundante sobre o efeito de Pigmaleão nas práticas dos líderes, sejam eles pais, docentes ou treinadores desportivos, já o mesmo não se verifica no sentido contrário. E, todavia, nada impede supor que as expectativas que, por exemplo, os alunos desenvolvem relativamente aos seus professores, possam condicionar os seus comportamentos de forma mais ou menos cooperativa. Michel Gilly (1989) refere um caso experimental que, embora isolado, valida tal hipótese, confirmando que os alunos adaptam os seus comportamentos às expectativas que desenvolvem sobre os estilos dos seus futuros docentes. A experiência em causa adopta de certo modo o paradigma de Kurt Lewin, mas com maior controlo experimental. Diferentes grupos de alunos visionaram um filme de 12 minutos onde o seu futuro professor se comportava em termos mais "autoritários" ou mais "democráticos". Esse mesmo professor adoptava, todavia, um estilo "neutro" para com os grupos experimentais que em seguida leccionou, mas ignorando qual a modalidade do filme que cada um dos grupos tinha previamente visionado, precisamente para neutralizar qualquer possíveltendência comportamental. Os resultados confirmaram que os alunos percepcionavam o estilo do docente de acordo com as expectativas criadas pelo anterior visionamento do filme, embora o comportamento do docente fosse basicamente neutro em ambos os casos.

Tais resultados alertam para a importância decisiva das primeiras impressões, sejam elas formadas a partir da fama positiva ou negativa que precede o docente enquanto líder, resultantes dos primeiros contactos entre professores e alunos. $\bigcirc$ contexto escolar reveste-se, sob este aspecto, de características sui-generis de particular complexidade, derivadas da diversidade de professores e de conteúdos programáticos aque os alunos são expostos e isto ao longo do arco de vida que conduz da infância à idade adulta.

\section{Imagens recíprocas}

A Escola não é um espaço organizacional isolado, existindo num vácuo social. Insere-se em contextos mais amplos tais como as culturas nacionais e regionais, as instituições politicas e as células familiares, todas elas em interacção e condicionamento recíprocos. Tal dinâmica societal é geradora de representações, não apenas ao nível macro-sistémico, descrito por Foucault, 
mas também a níveis de carácter mais local. A teoria das representações sociais, introduzida por Serge Moscovici em 1961, fornece um quadro conceptual e instrumentos metodológicos que podem contribuir para uma melhor compreensão das interacções disciplinares, no sentido amplo, no contexto da Escola. A investigação neste domínio tem sido desenvolvida sobretudo em língua francesa, ainda que, recentemente, se verifique uma maior abertura para além dos círculos francófonos.

$\bigcirc$ interesse desta abordagem reside nas pistas que fornece para a centralidade do significado que os diferentes actores atribuem aos papéis que integram o sistema e que condicionam tanto as expectativas como as práticas. Podemos presumir que os equilíbrios societais são sempre precários e por isso mesmo dinâmicos, sendo frágil a convergência entre as representações do papel da Escola e dos seus agentes por ela própria, pelas agências governamentais ou ainda pelas famílias e, last but not least, pelos próprios utentes do sistema - os alunos, cuja voz autónoma tende a recuar cada vez mais em termos de protagonismo precoce. A pesquisa das representações desenvolvidas nestes diferentes níveis ajuda a identificar conflitos latentes, bem como a hipotetizar causas para conflitos manifestos ou mesmo para antecipar tendências 40 de mudança mais ou menos estruturais na arquitectura do próprio sistema, bem como nas atitudes dos seus actores. As questões que naturalmente ocorrem, e que são as que esta perspectiva teórica analisa, giram em torno das representações do que uns e outros e eles próprios consideram ser (bom) professor, (bom) ensino, (bom) comportamento, seja na sala de aula, no recreio, na família ou na rua.

Passamos para os domínios dos valores sempre subjacentes aos juízos de facto e à legitimidade das intervenções. A evidência de que dispomos, reunida sobretudo em autores de língua francesa, indica que é detectável alguma convergência sistémica que, aliás, legitima a congruência entre expectativas, papéis e práticas associadas, a par de uma conflitualidade moderada que constitui a condição da própria dinâmica social, visível sobretudo em tempo de aceleração de mudança. Segundo apurou nomeadamente Gilly (1989), sintetizando a pesquisa neste domínio, as representações sociais são reveladoras das estratégias de legitimação na forma como procuram resolver a contradição básica de um sistema centrado no igualitarismo, que os resultados consistentemente põem em causa, e a fortiori com a massificação operada por via democrática. Confrontam-se representações que ora atribuem as causas do 
sucesso a factores psicológicos individuais, ora a causas de carácter socio-económico ou ainda a combinações sincréticas de ambos os factores, com as consequências determinantes para as expectativas subjacentes às interacções entre os próprios agentes directamente envolvidos, ou seja, professores e alunos.

$\bigcirc$ que é para um professor um bom aluno, o aluno modelo? Que critérios, ou seja, que grelha mental utiliza o professor para proceder às suas avaliações? A pesquisa neste domínio sugere que os professores tendem, no que se refere aos aspectos relacionados com a transmissão dos saberes (instrução), a dar prioridade às atitudes para com o trabalho, ou seja, pelo grau de participação e motivação, colocando em segundo lugar os valores cognitivos e, quanto a estes, atribuindo mais relevo ao pensamento convergente - qualidade de assimilação -, do que ao pensamento divergente - criatividade e inovação. No que se refere aos aspectos da gestão disciplinar, o acento é igualmente colocado na conformidade às regras sociais e morais da vida escolar que, por seu turno, contribua para um funcionamento do grupo facilitador da aquisição dos conhecimentos no contexto pedagógico directivo e hierárquico.

Tais representações estão em consonância com as expectativas do sistema institucional, constituindo deste modo, para recorrer à nomenclatura de Serge Moscovici (1961), representações hegemónicas igualmente partilhadas e interiorizadas por professores, alunos e familiares, ainda que com matizes locais ou mesmo tendências alternativas latentes.

A partir destes critérios a priori, desenham-se os protótipos tanto para os bons como para os maus alunos. Os bons alunos são, por um lado, os alunos aplicados e disciplinados, enquanto os maus alunos são passivos, pouco trabathadores e indisciplinados. Vemos aqui os dois processos básicos da formação de representações sociais. Por um lado, a ancoragem, ou seja, a categorização num sistema conceptual previamente estabilizado e familiar e, por outro lado, a objectivação em protótipos, ou seja, em imagens mais ou menos esquemáticas e inevitavelmente redutoras. De acordo com autores como Londeix (1982) ou Weiss (1984), cada tipo de bom aluno corresponderia a um modelo de escola: ao aluno inteligente e dinâmico, a escola das elites; e ao aluno aplicado, disciplinado e perseverante, o modelo da escola meritocrática.

Quanto às representações dos professores pelos alunos, verifica-se igualmente o seu valor adaptativo e funcional, na medida em que correspondem em grande medida às motivações dos alunos e às expectativas que desenvolvem 
relativamente aos docentes.É certo que há evolução com a idade, mas os três factores mais frequentemente citados ao nível do secundário são (1) a empatia nas relações com o aluno, (2) a organização do ensino e (3) a qualidade na forma de explicar.

A característica todavia mais central é a empatia, ou seja, a qualidade das relações sócio-afectivas expressas em termos de calor humano, benevolência, disponibilidade e atenção individualizada. $\bigcirc$ que alerta e igualmente parece validar o papel do professor enquanto líder transformacional, atento à diversidade da rede relacional que é suposto gerir,mas dificilmente operacionalizável em regimes escolares massificados.

\section{Conflitos funcionais e disfuncionais}

A Escola constitui, pela sua natureza, um locus de conflito e um contexto onde porventura uma das características mais requeridas para uma liderança eficaz consiste justamente na competência para gerir conflitos. Isto na acepção restrita das interacções professor-aluno ou aluno-aluno e abstraindo das inter-

42 -faces não menos complexas que opõem governos e sindicatos, tal como se observa actualmente na sociedade portuguesa, e que terão certamente consequências na governação das escolas e nas práticas pedagógicas.

ensino enquanto acto de liderança e, em última análise,enquanto exercício do poder, por legitimado que esteja, implica sempre uma referência a constrangimentos disciplinares, ou seja, a conflitos que, namelhor das hipóteses e como ensinou Freud, se acham aprisionados dentro dos limites intra-psíquicos. Tal processo demora tempo,faz parte do processo de socialização que começa com a família e que a escola ajuda a consolidar mas não a substituir,como por vezes parece exigir-se. Tal como lembra Foucault (1975), o poder é sempre bio-poder, passa sempre por forçar o corpo, por domar vontades, por adiar gratificações. Séculos de experiência têm contudo ajudado a introduzir progressos assinaláveis, ainda que seja porventura utópico ou mesmo indesejável imaginar quadros inter-relacionais isentos de conflito, pelo menos em certas circunstâncias. É habitual distinguir-se entre conflitos cognitivos e conflitos afectivos, considerando aqueles como funcionais e estes últimos como disfuncionais.

Conflitos cognitivos são os relacionados com a execução das tarefas que, no caso vertente, se centram nos próprios conteúdos do ensino/ 
aprendizagem e no papel que a multiplicação de perspectivas e da análise crítica exercem na progressão dos conhecimentos e sobretudo na agilização do entendimento. Isto conduz-nos aos problemas complexos da psicopedagogia, que excedem o âmbito deste texto. Mas será de referir, ainda que de passagem, os trabalhos desenvolvidos na sequência de Piaget, designadamente por Doise, Mugny e Perret-Clermont, sugerindo que tais conflitos serão tanto mais produtivos quanto mais articularem factores sociais e factores cognitivos, o que poderá justificar estratégias pedagógicas de trabalho em grupo.

Estudantes e professores sabem há muito que o estudo conjunto com os pares oferece vantagens, precisamente por estimular a descentração e a capacidade crítica. É também igualmente de referir a contribuição de Vygotsky, com o conceito que introduziu de zona de distância próxima, tão do agrado de Bruner,e que, analogamente aos níveis de aspiração de Kurt Lewin, constitui uma estratégia não menos válida de estabelecimento de objectivos difíceis maspossíveis, visando uma aceleração racional e graduada da aprendizagem.

Poderia, aliás, argumentar-se que os conflitos são sempre sócio-cognitivos, ainda que a componente social tenda a esbater-se em situações de puro entendimento, se é que tais situações existem. Mas mesmo nesse caso o factor social estará presente enquanto mediador da relação sujeito-objecto, sob a forma de paradigmas e representações não sujeitos a negociação.

Nos casos em que predomina a relação afectiva e sobretudo quando esta se traduz em oposição de vontades, é o factor cognitivo que assume o papel de mediação, a qual, em casos extremos mas nem por isso menos frequentes, poderá ser incapaz de exercer o seu papel regulador. Daí, de resto, o juízo negativo atribuído aos conflitos sócio-afectivos e à estratégia recomendada de os prevenir ou, quando muito, manter latentes, já que, uma vez declarados ou manifestos, tendem a escalar e dificilmente conduzem a soluções com benefícios para ambos os lados (win-win).

No que se refere aos conflitos sócio-afectivos na sala de aula, um meio altamente codificado por normas explícitas e implícitas, a gestão/regulação das interacções conducentes a um clima preventivo depende sobretudo da competência relacional dos docentes. No espaço muitas vezes desregulado e quase selvagem do recreio, a conflitualidade inter-pares pode degenerar e degenera com frequência nos fenómenos de intimidação (bullying) física e/ ou verbal, onde o exercício do poder recua para a sua expressão mais arcaica da 
força e da arbitrariedade. Em Portugal ainda não se matam uns aos outros, mas já estivemos mais longe de tal poder ser sequer concebível. Não se trata todavia de compartimentos estanques. Sabemos, desde Bandura, que a metáfora hidráulica do escape como estratégia de regulação da violência conduz, pelo contrário, a efeitos de reforço, pelo que a prevenção não pode limitar-se ao nível local da sala de aula. De resto, a representação que atribui a indisciplina à permissividade ou mesmo estimulação extra-escolar baseia-se na mesma lógica de recusa dos processos compensatórios e das válvulas de escape. Mais eficazes parecem revelar-se os mecanismos de sublimação, igualmente baseados nas metáforas Freudianas de um quantum de energia, cujo inevitável acting out é todaviasusceptível de ser moderado através de controles inibitórios e, por isso mesmo, facilitadores duma orientação para objectivos socialmente nómicos.

A literatura sobre a disciplina e indisciplina na Escola e formas como poderá ser eficazmente regulada é relativamente vasta e bem fundamentada. Em português podemos identificar muitos textos competentes propostos por autores, certamente entre muitos outros, como Feliciano Veiga (2007), João Amado (2000), José Caeiro e Pedro Delgado (2005), Maria Teresa Estrela (2002) e Saúl Neves de Jesus (1 999), convergentes tanto nos diagnósticos 44 como nas terapêuticas, e que muito poderão contribuir para ajudar a tarefa do professor que não apenas tem que gerir um programa mas também que liderar grupos quase sempre heterogéneos e com níveis de motivação e empenho muito variáveis. Para além da oferta nacional, teoricamente suficiente, o leitor interessado tem actualmente acesso a uma informação pletórica e mesmo a um conjunto de receitas práticas oferecidas por via da Internet, onde poderá confirmar muito do que o bom senso e as representações compartilhadas há muito recomendam. Também através dessas leituras se conclui da bondade da velha fórmula de que mais vale prevenir do que remediar e que,uma vez o conflito latente tornado manifesto sob formas de carácter anómico, senão mesmo violento, difícil será que a situação não se resolva sem perdas para todas as partes envolvidas. Daí também a táctica dospequenos passos, muito ao gosto da psicologia do reforço, mas cuja eficácia se acha largamente validada pela evidência empírica. 


\section{Ser professor não é fácil}

A literatura sobre as competências dos líderes distingue, desde a década de 50, com Tannenbaum (TANNENBAUM; WESCHLER; MASSARIK, 1961 l, entre competências técnicas, competências relacionais e competências estratégicas. Dado o seu grau de abstracção, a distinção aplica-se urbi et orbi e será dificilmente falsificável. Mas tem valor heurístico na medida em que fornece um quadro conceptual de geometria variável, com categorias receptivas aos mais diversos conteúdos substantivos. Em termos organizacionais é igualmente consensual admitir-se que o nível hierárquico implica um balanceamento entre competências técnicas - sobretudo requeridas em níveis operacionais -, e competências estratégicas - requeridas sobretudo aos níveis políticos das orientações globais. As competências relacionais seriam todavia indispensáveis a todos os níveis da hierarquia, constituindo uma condição necessária de eficácia tanto para sargentos como para generais. A escola é, como penso ter ficado claro, uma organização com as suas características específicas, onde os professores desempenham funções de gestores e líderes, cujas competências são dirigidas para a formação e transformação dos seus próprios utentes e parciais colaboradores. E note-se que me refiro aqui exclusivamente à sala de aula e não aos múltiplos papéis da hierarquia do sistema a montante da sala de aula.

Também aqui a tríade das competências tem a sua aplicação. Haverá porventura docentes que investem sobretudo nos aspectos técnicos, ou seja, nos saberes de que são especialistase, na melhor das hipóteses, nas formas mais eficazes de garantir a sua transmissão e assimilação. Trata-se duma estratégia de tipo universitário ou para-universitário, que tende a secundarizar e mesmo a desvalorizar as componentes pedagógicas e mais ainda as relacionais, com implicações disciplinares. A representação subjacente, consciente ou inconsciente, é investir nos poderes de informação e competência, por forma a projectar a imagem da autoridade especializada, supostamente suficiente para legitimar o respeito, a admiração e a obediência.Por si só, e sobretudo com audiências de menor grau de maturidade, poderá não ser suficiente, mas nem por isso deixa de ter lugar quando exercida em termos comparativos e também quando associada a conteúdos disciplinares com elevada legitimidade epistemológica, como é o caso da matemática e da física. Tal como alerta Foucault, há correlação entre saberes e poderes e não será por acaso que a designação de disciplina se aplique tanto a conteúdos programáticos como 
a comportamentos regrados, sistemáticos e obedientes. Possivelmente, também aqui, os professores são todos iguais mas há uns mais iguais do que outros.

No que se refere àscompetências estratégicas, podemos distinguir, com Suchodolski (1960), entre as pedagogias da essência e as pedagogias da existência, aquelas baseadas na visão humanista do cidadão a construir através do professor-mentor, em contraste como modelode carácter mais horizontal inspirado pelas ciências sociais, em que predominam a personalização pedagógica, o respeito pelo aluno e o desenvolvimento da cooperação e da iniciativa. Em grande medida, se as pedagogias da existência acolhem hoje uma aceitação mais generalizada, sendo inclusivamente a que se declara em termos públicos e oficiais, isso não significa que a inevitável inércia não continue a reproduzir os modelos de assimetria vertical. Nas pedagogias existenciais adquirem saliência as competências relacionais tão acentuadas nas representações do professor ideal pelos alunos.

mix das competências dos professores-líderes resulta, em parte, de opções individuais mas também, senão mesmo sobretudo, das envolventes representacionais e das culturas locais. Não será prudente arriscar qualquer diagnóstico aplicável ao caso português, ele próprio igualmente marcado pela 46 diversidade mas também por alguma indefinição estratégica que não tem contribuído para a estabilização do sistema. Sabemos todavia que, em tempos de deriva e de mudança acelerada sobre governação escolar e sobre pedagogia, haverá razões de inquietação e de crescente perplexidade.

Voltando ao ponto de partida, aos estudos pioneiros de Lewin e associados, se é certo que as receitas "democráticas" não constituem panaceia, nem tão-pouco permitiram uma validação de um modelo geral de liderança adequado à situação escolar, é todavia menos contestável que a alternativa laisser faire, baseada no alheamento e na impunidade, é a pior alternativa, conduzindo a níveis intoleráveis tanto de aproveitamento como de indisciplina. Não será todavia uma hipótese tão remota como se possa julgar, se atendermos a que as nossas organizações e as instituições propiciam por vezes climas anómicos de cumplicidade e impunidade generalizadas, onde a "a circunferência está em todo o lado e o centro em lado algum". 


\section{Referências}

ADAIR, John. Leadership and motivation. London/Great Britain: Kogan Page Limited, 2006.

ALMEIDA, Ana Maria Tomás de. Portugal. In CATALANO, Richard; JUNGER-TAS, Josine; MORITA, Yohii; OLWEUS, DAN; SLEE, Philip; SMITH, Peter (Ed.). The nature of school bullying. A cross-national perspective. London: Routledge, 1999.

AMADO, João da Silva. Interacção pedagógica e indisciplina na aula. Porto: ASA, 2000.

AMADO, João da Silva; FREIRE, Isabel. Indisciplina e violência na escola. Porto: ASA, 2002.

CAEIRO, Jose; DELGADO, Pedro. Indisciplina em contexto escolar. Lisboa: Instituto Piaget, 2005.

CATELL, Raymond. Concepts and Methods in the Measurement of Group Synthatily. In: HARE, Alexander Paul; BORGATTA, Edgar; BALES, Robert (Ed.) Small groups. New York: Knopf, 1961.

ESTRELA, Maria Teresa. Relação pedagógica, disciplina e indisciplina na aula. 4. ed. Porto: Porto Editora, 2002.

FOUCAULT, Michel. Surveiller et punir. Paris: Gallimard, 1975.

FRENCH JR, John; RAVEN, Bertram. The bases of social Power. In CARTWRIGHT, Dorwin. Studies in social power. Ann Arbor, Michigan: Institut for Social Research, 1959.

GILLY, Michel. Les représentations sociales dans le champ éducatif. In JODELET, Denise (Dir.). Les représentations sociales. Paris: PUF, 1989.

GOFFMAN, Erving. Asylums: essays on the social situation of mental patients and other inmates. New York: Anchor Book, 1961.

JESUS, Samuel. Como prevenir e resolver o stress dos professores e a indisciplinados alunos? Porto: ASA, 1999.

KERR, Steven; JERMIER, John. Substitutes for leadership: Their meaning and measurement. Organizational Behavior and Human Performance, Elsevier Publisher, Amsterdam, v. 22, n. 3, p. 375-403, sept./dec. 1978.

LEWIN, Kurt; LIPPIT, Ron. An experimental approach to the study of autocracy and democracy: a preliminary note. Sociometry, London, v. 1, n. 4, p. 292-300, 1938. (Trimestral). 
LEWIN, Kurt; LIPPIT, Ron; WHITE, Robert. Patterns of aggressive behaviour in experimentallycreated "social climates". Journal of Social Psychology (Trimestral), London, v. 10, p. 271-299, 1939.

LONDEIX, Hervé. Structure factorielle de l'opinion des professeurs sur leurs élèves. L'orientation scolaire et professionnelle, Paris, v. 11, n. 2, avril/juin, p. 169-190, 1982.

MOSCOVICl, Serge. La psychanalyse, son image et son public. Paris: PUF, 1961.

ROSENTHAL, Robert; JACOBSON, Lenore. Pygmalion in the classroom. New York: Rinehart \& Winston, 1968.

SEBASTIÃO, João; CAMPOS, Joana; ALMEIDA, Ana Maria Tomás de. Portugal. The gap between the political agenda and local initiatives. In: SMITH, Peter (Ed.). Violence in schools. London: Routledge, 2003.

SUCHODOLSKI, Bogdan. La pédagogie et les grands courants philosophiques. Paris: Scarabée, 1960.

TANNENBAUM, Robert; WESCHLER, Irving; MASSARIK Fred. Leadership and Organization: abehavioral approach. New York: McGraw Hill Book, 1961.

48 TWAIN, Mark. Autobiography of Mark Twain: volume 1 (Mark Twain Papers). Oakland, CA: University of California Press, 2012.

VEIGA, Feliciano. Indisciplina e violência na escola: práticas comunicacionais para professores e pais. 3. ed. Coimbra: Almedina, 2007.

WEBER, Max. Os três tipos puros de dominação legítima. Tradução Artur Morão. Lisboa: Tribuna da História, 2005.

WEISS, Jacques. Individualité et réussite scolaire. Berne: Peter Lang, 1984.

Prof. Dr. Jorge Correia Jesuíno Instituto Superior de Ciências do Trabalho e Empresas Instituto Universitário de Lisboa Professor Catedrático Emérito do ISCTE-IUL E-mail | jorge.correia.jesuino@gmail.com

Recebido 27 jul. 2014 Aceito 25 ago. 2014 